\title{
Culturally Based Education for Sustainability-Insights from a Pioneering Ultraorthodox City in Israel
}

\author{
Iris Alkaher ${ }^{1, *}$, Daphne Goldman ${ }^{2}\left(\mathbb{D}\right.$ and Gonen Sagy ${ }^{3}$ \\ 1 Faculty of Science, Kibbutzim College of Education Technology and the Arts, Tel Aviv 6250769, Israel \\ 2 Department of Environmental Studies and Agriculture, Faculty of Education, Beit Berl College, \\ Doar Na 44905, Israel; dafnag@netvision.net.il \\ 3 Independent Researcher, Ottawa, ON, Canada; sagygonen@gmail.com \\ * Correspondence: iris.alkaher@smkb.ac.il; Tel.: +972-3-6902-324
}

Received: 21 August 2018; Accepted: 11 October 2018; Published: 16 October 2018

\begin{abstract}
Because culture affects the way people perceive human-nature relationships, it is acknowledged as a crucial component of sustainability. Israel has made efforts to involve cultural groups in education-for-sustainability (EfS). However, EfS within minorities still lags behind the dominant social majority. This study addressed incorporating EfS in the ultraorthodox sector ("ultraorthodoxing" EfS), focusing on a pioneering ultraorthodox municipality. In this interpretive study, interviews were conducted with nine stakeholders that hold key-positions regarding EfS policy-making. It explored how sustainability is introduced into ultraorthodox discourse and promoted in this community. Challenges to incorporating EfS include low environmentalism among the ultraorthodox and cultural-religious barriers. The findings indicate several directions of activity implemented by the Municipality to adapt EfS to ultraorthodox values and worldviews. The study suggests several principles for incorporating EfS in diverse cultural groups within multicultural societies (for example, allocating leaders from within the cultural group and developing their professional expertise, and establishing productive external-internal partnerships). Based on the findings, we suggest that implementing the particularistic approach within specific communities provides the means for empowering them, and is a necessary stage towards the participation of such cultural groups in pluralistic dialogue in wider society.
\end{abstract}

Keywords: ultraorthodox; education for sustainability; multiculturalism; multicultural environmental education; minorities

\section{Introduction}

This study focuses on incorporating education for sustainability (EfS) in the ultraorthodox (UO) sector of the Israeli society. Israel is a multicultural society, comprised of $74.6 \%$ Jews, $20.9 \%$ Arabs (83\% Muslim, 9\% Christian, 8\% Druze) and 4.5\% others [1]. Based on levels of religiosity, the Jewish population itself is diverse: secular $(43 \%)$, non-religious-traditional $(23 \%)$, religious traditional $(15 \%)$, religious (10\%) and the extremely religious UO ("Haredi", 9\%) [1]. This multiculturalism in Israeli society, similar to other multicultural societies worldwide, brings into play various norms, traditions, beliefs and behaviors, as well as different understandings and perceptions of human-nature relationships. As culture affects the way people perceive the world and interact with each other and nature, it is increasingly acknowledged as a crucial component of sustainability: study [2] includes cultural diversity as one dimension to address within the framework of the 2030 sustainable development goals. Despite this, the cultural dimension still receives less attention in EfS practice, which may impede promoting sustainability in societies, which, in a global world, are becoming increasingly multicultural [3]. Just as biodiversity is essential for the sustainability and resilience of 
ecosystems, cultural diversity is crucial for human societies: environmental-social sustainability can be achieved by positively utilizing cultural diversity $[4,5]$. Acknowledging diversity implies providing equal opportunities for culturally diverse groups, especially minorities, to participate in and contribute to environmental discourse [6-8]. Accordingly, including all cultural groups within environmental discourse is essential for achieving a sustainable Israeli society $[9,10]$. This study focuses on the UO minority, which is a segregated group by choice.

Education for sustainability is a contemporary approach within the broader area of environmental education that seeks to empower people, as individuals and communities, to embrace responsibility for promoting a sustainable future, and foster environmental stewardship [11,12]. EfS aims to cultivate the capacity and the tendency to seek the ultimate human and socially-oriented root-causes of environmental issues and challenges. EfS especially emphasizes democratic processes, the values of equity and justice, and acknowledges social-cultural diversity [11]. It aims to build human capacity to live more sustainably. EfS is a holistic approach that attempts to integrate environment and development issues and puts emphasis on values education and critical education [13] EfS is human-centered and encourages critical thinking and active citizenship.

Israel has made efforts to involve cultural groups in EfS discourse (e.g., UO and Arab populations). Despite this, EfS within these minorities still lags behind the secular Jewish majority [14], reflecting various external and internal challenges to incorporating it and promoting sustainability within these communities. These researchers [14] are appealing to change the situation in which the UO and Arab minorities are only partially involved in decision-making and policy-making processes. This study provides insights into possible ways to address this challenge.

The choice of the UO community to isolate itself socially and culturally (towards preserving their Jewish values and identity) is a major factor challenging their inclusion in various processes currently promoted by the government and authorities. For example, their independent system of education [15], one aspect of their segregation-by-choice, reduces their exposure to the collaborative developments promoted by the Ministry of Education (MoE) and Ministry of Environmental Protection (MoEP) to integrate EfS into the education system [16]. It also challenges government efforts to involve UO municipalities in incorporating sustainability within their communities. Currently, in most UO municipalities, an environmental unit is absent, addressing local environmental issues is limited, and involving the citizens in environmentally responsible behavior is low. This raises the question of how to integrate this community into national efforts to implement sustainable development, including the educational arena.

The present study addresses this challenge. It focuses on the unique case of ultraorthodox going-green city (pseudonym, hereafter called "UGC"), in central Israel, which made a strategic and political decision to establish an environmental department within its municipality and appoint an EfS coordinator. Underlying this decision was the aim to enhance inclusion of urban sustainability within the municipality's agenda, including a systemic approach to bringing EfS into the community. This case provides a unique opportunity to explore such a process in a pioneering city, investigating it from the perspective of nine key administrators from within the municipality and external organizations directly involved in the process. The aim of this study is to identify promoters and barriers to bringing the environment into UO public discourse and promoting sustainability within the community, and to provide insights for addressing the obstacles, focusing on the perspective of the leaders of this process-of-change. Accordingly, the study addressed the following questions: (1) What are the main challenges to promoting EfS within this UO community? (2) What are the main developments and actions implemented to promote EfS within the local community and in what ways are these actions adapted to UO values and norms? (3) What do the stakeholders perceive as the main achievements and major ongoing challenges? (Figure 1). 


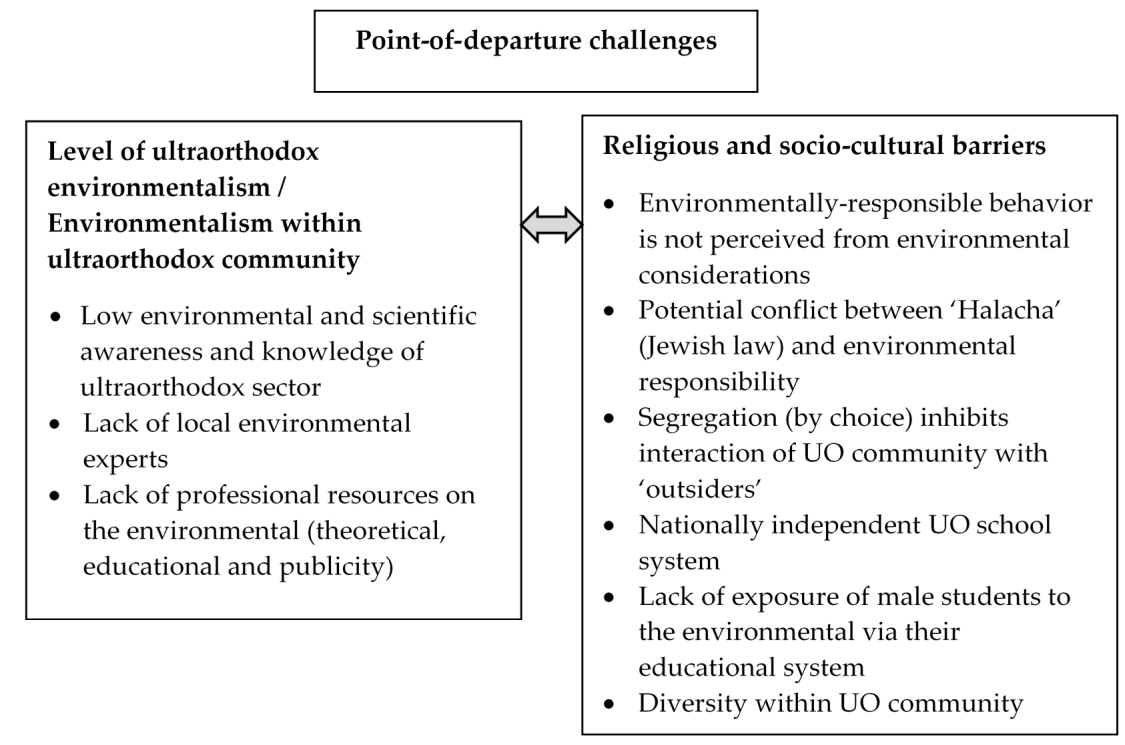

Addressing the challenges by the municipal environmental department (within the local population and at the interface with outside organizations (see Tables 2 and 3 )

Ongoing challenges (see Table 4)

\begin{tabular}{|l|l|l|}
$\begin{array}{l}\text { Increasing environmental literacy of } \\
\text { ultraorthodox community }\end{array}$ \\
$\begin{array}{l}\text { - Addressing 'the commons' } \\
\text { Raising attachment to local urban } \\
\text { nature and lack of nature }\end{array}$
\end{tabular}

Figure 1. Framework for identifying the main challenges and actions concerning incorporating education-for-sustainability (EfS) within the ultraorthodox (UO) community, ultraorthodox going-green city (UGC) municipality.

The choice to provide answers to these questions by exploring the leaders' point of view is valuable in view of their central role as establishers of the process-of-change as part of the municipality's policy, and their commitment to leading long-term change within their community. The first stage in exploring the complex and extensive process of change occurring within the community is to gain insight, via this study, concerning the rational and reasoning that lead these leaders to conduct the specific actions they undertook. These may provide the foundations for further exploration of the process, from the perspective of the citizens of the community. Furthermore, exploring the process this pioneering municipality is experiencing provides insights that may contribute to designing similar processes for other UO communities in Israel, and from a broader international perspective, may suggest ways to involve other minorities or segregated cultural groups in the incorporation of EfS.

This study's point of departure is that the establishment of an environmental department in this municipality reflects the decision-makers' understanding that addressing the environmental 
challenges of the city, including EfS, requires adapting solutions to the cultural attributes of the UO society and collaborating with participants outside the UO society, initially government institutions. This is a two-way process in which the municipality needs to find ways to adapt itself to institutions external to its community, and these institutions must adapt themselves to the community's characteristics. This point of departure situates this study in the theoretical field of multiculturalism and multicultural education.

\subsection{Characteristics of the Israeli Ultraorthodox Society}

Israel is home to the largest UO population in the world, 900,000, most of whom live in several urban neighborhoods. Additionally, there are a few exclusive UO cities and settlements. While often perceived from the outside as uniform, the UO society is diverse and grouped into different streams according to specific rabbinical courts [16]. Despite this diversity, some common attributes characterize this sector as a whole. Significantly, the UO choose to segregate themselves from the wider Israeli society to preserve their unique lifestyle and extreme religious worldview. Their segregation is reflected, for the most part, in where they choose to live, their education system, dress code, religious institutions and political affiliation [17]. Though Israel provides a modern, high-tech lifestyle to most citizens, the UO society accepts modern circumstances within strict limits and regards itself as a direct continuance of the authentic Judaic way of life. For example, only $41 \%$ of the UO population uses the internet as compared to $80 \%$ in the total Israeli population.

The UO community lives according to the Jewish religious laws (namely, halacha, literally meaning "the way to behave", which is the collective body of Jewish religious laws based on written and oral Tora.), interpreting the Jewish literary sources in the severest manner. As an extremely conservative society, the UO follow their particular rabbi, who serves not only as a spiritual leader, but also as their supreme authority for all aspects of their lives, including decisions concerning contemporary dilemmas. This society still reflects a strongly patriarchal ethos and traditional family structure in which women hold the responsibility of running the household, educating the children and providing the conditions that enable their husbands to devote time to Jewish religious studies, which hold supreme value and are the men's role $[18,19]$. The UO education system is independent of the national public school system [16]. It is divided into two main tracks: the unofficial nationally recognized schools (comprising $57 \%$ of the male and $95 \%$ of the female UO students), which are obligated to the core national educational curricula, and the independent schools, which are not obligated to the national standards and have independent curricula. Gender segregation, which characterizes this community, starts very early in the school system: three-year-old boys study in the heder (Heder (literally 'room") — the special educational framework for ultraorthodox boys from toddler (age three) to Bar-mitzvah (age 13) where they learn how to read and study the Tora and other canonical sources.). Throughout their school years, from the heder to the yeshiva (Yeshiva (literally "sitting") - the special educationally framework for post Bar-mitzvah boys), the core of male learning is Jewish religious studies, while other subjects are marginalized, since they are considered as a waste of time that should be devoted to religious studies [20]. In the female school system, from pre-school throughout high school, students receive more exposure to non-religious subjects, including science and humanistic studies, although this is still much less than the national curriculum. Only $19 \%$ of the UO have an academic degree.

The UO population is one of the lowest socioeconomic status sectors in Israel; the proportion of population below the poverty line is significantly higher (52\% of the population) than the corresponding rate in the total Israeli population (19\%). Per capita, income is $47 \%$ lower than the corresponding amount in Israel, a major reason being the high percentage of men devoted to religious studies. This is also reflected in gender differences in the UO workforce: $78 \%$ of the women work ( $53 \%$ in education), while only $53 \%$ of the men work ( $33 \%$ in education) [17].

It is noteworthy that the UO society is currently undergoing a process of transition in many aspects (e.g., higher education, mandatory military service, workforce), leading to their greater integration into the wider Israeli society [21]. The decision to promote sustainability and EfS within UGC, including increased interaction with non-religious organizations, reflects this transition. 


\subsection{Judaism, Environment and EfS in the UO Society}

From the environmental perspective, the UO population presents a complex picture. On the one hand, the lifestyle of this social sector is characterized by low consumption levels in comparison to the secular population [22]. While this may be an outcome of the low socioeconomic status of this population, it more significantly reflects this community's observance of a strict religious lifestyle. The behavior of observant Jews, including their behavior towards the environment, is largely regulated by halacha [23]. Many aspects of halacha lead to a resource-conservative and modest lifestyle. A central pillar of Jewish and UO beliefs is that God exists in everything and at all times: humans, animals, vegetation and lifeless objects all exist because of God's presence within them, hence human interactions with every living or lifeless object have meaning spiritually and ethically. Jewish halacha and literary sources (e.g., the Bible, Talmud, Midrashic literature, Kabbala) are rich in their references to nature, human-nature relationships and humans' responsibility to protect the environment [24,25], which emphasizes that complete interdependence between humans and the natural world is a recurring theme in Jewish religious narrative. Thus, orthodox practices can be considered more compatible with the environment in comparison to modern society's lifestyles [26], although the reasoning behind this is not directly environmental. While halacha reflects clear norms concerning desirable ways of living with respect to nature and the environment--topics inherent to contemporary sustainability discourse-the human-environment relationship is treated from the perspective of the essence of human's life: human existence and living sustainably are deeply tied to the commitment to obey God's commands [26]. Although the anthropocentric view of human dominating over nature for his own benefit is a prevailing theme in Judaism, many Jewish texts represent ideas and principles that are consistent with the ecocentric view of human nature relationships. These impose restrictions on how, when and to what extent people may use natural resources [25], and imply sustainable ways of living [27]. Despite this, a pervasive perception among the Israeli public is that the UO society is less environmental or non-environmental [28], as reflected, among other things, in run-down urban residential areas characterized by general neglect of the surroundings and public domain.

Shilhav and Kaplan [29] claim that a tension exists between the high position the human-environment relationship holds within Jewish sources and the ethical obligation of Judaism to respect and protect nature and the environment, as opposed to a distancing from this environmental consciousness in practice. Vogel [26] identifies four central ideas of Judaism that may explain this tension: protecting the natural world is not the highest imperative; human life is more important than non-human life; nature was created by God to be utilized and enjoyed as well as preserved; and just as humans can threaten nature, nature can threaten humans. These are relevant to the current discourse concerning Judaism's ethical relationship between humans and the natural world. Shilhav and Kaplan [29], who compared the environmental quality among different UO neighborhoods, concluded that the low socioeconomic status and demographic characteristics of the community only partially explain the environmental problems that characterize their neighborhoods, while lack of awareness (of both the UO community and government authorities) is also a significant factor. The strategic move made by UGC to promote sustainability within their city aligns with these authors' recommendation for intensive action to increase the environmental awareness of this community.

\subsection{Multiculturalism and Multicultural Environmental Education}

Marginalized cultural groups are often disregarded or under-represented in sustainability discourse and decision-making processes; these groups often suffer from environmental problems more than dominant groups, and their needs are disregarded. Marouli [30] claims that understanding of environmental issues and their proposed solutions are culturally limited to and by the perceptions of the dominant group. Multiculturalism seeks to address this issue. This ideology seeks to adapt people's beliefs and behaviors to the multicultural nature of societies and communities worldwide [30]. It embodies three different meanings: demographic, which refers to the existence of cultural ethnic diversity; ideological, which underlines the legitimacy of recognizing diverse identity groups; and from 
a programmatic political sense, it refers to policies designed to respond to the problems posed by diversity, such as power relations, dominance and access to resources [30,31].

Multicultural education developed as the educational response, aimed at promoting multiculturalism. It refers to two practices: teaching in a multicultural society and teaching about cultural diversity [32]. This study falls under the practice of teaching within a multicultural society and addresses the challenge of how to adapt EfS to a specific cultural group. Two major approaches can be identified regarding multicultural education: pluralistic and particularistic [33]. The pluralistic approach emphasizes teaching learners'multiculturalism with the aim of acknowledging and respecting cultural diversity, based on the understanding that no one culture is "above" others and therefore social and political hierarchy is unacceptable [34]. The particularistic approach focuses on differential education for each cultural group, emphasizing its unique culture and values based on the assumption that it is impossible to bridge cultural differences without leading to the dominance of the major cultures over minority ethnic groups. According to this approach, there is no one mandatory value frame, rather separate and particular education for different cultural groups [34-37]. Critical discourse exists concerning both approaches.

Nordstrom [32] claims that multicultural education and environmental education (EE) "are too close to be separate" as they share common values, goals, methodologies and content. Accordingly, multicultural environmental education (MEE) highlights the importance of reaching out to culturally diverse populations and understanding, respecting and utilizing their perspectives in EE. It "refers to increased access of culturally diverse- not only the dominant groups-to EE and increased representation of their worldviews in it" ([30], p. 28). MEE can be interpreted and enacted in several ways: EE that works with culturally diverse groups; educating ethnic minorities with the aim of empowering them to identify and assert their environmental rights; and as pedagogy for promoting cross-cultural understanding, respect and cooperation concerning environmental challenges. This study ties mainly into the second and third views.

Theoretical discourse in the area of multicultural education is increasing, and educational systems are increasingly explicitly addressing challenges resulting from increasingly multicultural societies [38], leading to the necessity of schools to prepare citizens for multicultural societies [34,39,40]. Within the broader area of multicultural education, this study focuses on environmental education. In the environmental context, the body of empirical work regarding its practice in multicultural settings (e.g., exploring the perspectives of participants in such programs) is still in its early stages. The following examples address some of such studies. In investigation of a Canadian (Canada is the pioneering country in adopting multiculturalism in its educational policy.) EE curriculum for multicultural school settings, teachers identified strategies and challenges in adapting EE to the multicultural context [39]. Examples of obstacles they encountered include conflicts between their own values and those of their students, and a lack of "common language" resulting from lack of common life experiences. It is reasonable to assume that such challenges are not unique to the Canadian context. Another example explored a MEE program implemented in Israel, that brought together Israeli Jewish and Arab (Bedouin) youth to learn collaboratively around environment projects aimed at protecting natural landscapes [41], focusing on the educators' and well as the learners' perspectives. Despite the educational program's benefits, it also highlighted several challenges for multicultural encounters, such as differences in teaching approaches and learning styles between the two cultural groups, as well as difficulties in communication due to language and cultural barriers. Despite such obstacles, the study revealed that beyond increasing the participants' awareness and willingness to protect the environment, all the participants acknowledged that the program enhanced intercultural understanding and acceptance, which decreased mutual prejudice [41,42].

School gardens provide a practical infrastructure for multicultural education and offer a specific opportunity in the context of MEE [43]. One example is an Australian multicultural school garden program implemented in a culturally-diverse school with a large proportion of migrant and refugee families [44]. The study found that the families' learning around the garden created 
a 'community-of-learners' and provided the opportunity to express the students' cultural heritage. Importantly, this program demonstrates development of a 'space' that facilitates a sense-of-belonging and forming connection to the local environment. This is supported by Richardson's [43] investigation of food-oriented and garden events in the USA, based on which he claims that such events are being developed to facilitate school-community partnerships, which are acknowledged as an important element of progressive multicultural agenda and education.

\section{Methodology}

\subsection{Study Site and Participants}

This study was conducted with the municipality of one of the largest UO cities in Israel, with a population of 188,000: $40 \%<0-14$ years, and is one of Israel's most densely urban areas $\left(54,075\right.$ people $\left./ \mathrm{km}^{2}\right)$. At the time of this study, there were 14,086 schoolchildren: $54 \%$ male and $46 \%$ female [29].

Nine administrators involved in implementing EfS in this city were interviewed; some of them were directly employed by UGC and others were employees of government and non-governmental organizations that provide EfS services to the municipality. All the participants hold key functions with respect to policy decisions concerning EfS and development and implementation of EfS within this UO community. All have academic and/or professional environment-related background. Table 1 outlines the participants' affiliations, positions and relevant responsibilities concerning EfS.

\subsection{Data Collection and Analysis}

This study implemented an interpretive qualitative approach [45]. The data were collected from two sources:

Documents - documents pertaining to environmental management and EfS activity conducted by the municipality were provided courtesy of the municipality. These provided information relevant to the second research question and included the chronological development of major environmental management actions, mainly EfS, within the municipality; the different ways in which it has been conducted since its initiation; different target groups within the UO community; the extent of activity within the different target groups and educational frameworks (formal and non-formal); and various logistic aspects pertaining to the implementation of EfS.

Interviews-Semi-structured, in-depth interviews were conducted with the participants. The interviews were the source of information pertaining to all research questions. These interviews were constructed around the following aspects: (a) How the stakeholders perceive the idea of EfS in the context of the UO community, and how these ideas should be translated into practice; (b) The ways they are involved in designing and implementing EfS in UGC's community; (c) Challenges they encounter in incorporating EfS within the UO community and how these are addressed; (d) Examples of achievements and successes of EfS in the context of UGC; (e) Insights they have gained from their experience, and recommendations with respect to promoting EfS within the UO population.

The three researchers conducted the interviews; in the majority of interviews, two of the researchers were present. The interviews were conducted at the participants' workplaces, lasted 60-90 $\mathrm{min}$ and were audiotaped (and transcribed verbatim). Inductive content analysis, according to Creswell, [46] and Strauss and Corbin [45], was conducted on the transcripts to identify emergent categories and themes focusing on: (a) different components of the major developments conducted by the UO municipality to promote EfS (see Table 2), (b) different areas of the EfS (see Table 3). For validation, analysis was conducted independently by the three researchers, each of whom created an initial categorization. These outcomes were compared and discussed among the researchers and revised until agreement was reached regarding the categories. Only these final outcomes are presented as the data. 
Table 1. Background data of the participants regarding their involvement in EfS in the ultraorthodox municipality (All names of participants and places are pseudonyms).

\begin{tabular}{|c|c|c|c|}
\hline $\begin{array}{l}\text { Name and Affiliation } \\
\text { to UO Community }\end{array}$ & Role and Position & Major Responsibility (Concerning EfS) & Duration of Involvement in EfS in UGC \\
\hline \multicolumn{4}{|c|}{ Municipality Employees } \\
\hline Abraham, male ultraorthodox & Head of the municipality Environmental Department & $\begin{array}{l}\text { Responsible for environmental management within the city; Established } \\
\text { the EE unit }\end{array}$ & 2012-present \\
\hline Rebecca, female ultraorthodox & $\begin{array}{l}\text { Eff-coordinator in the municipality, under the head of the } \\
\text { environmental department }\end{array}$ & $\begin{array}{l}\text { Responsible for all decisions (budgetary, administrative, logistic and } \\
\text { pedagogical) concerning EfS }\end{array}$ & 2012-present \\
\hline Sima, female ultraorthodox & $\begin{array}{l}\text { Vice EfS-coordinator; } \\
\text { Also employed as EE mentor in a leading environmental NGO }\end{array}$ & $\begin{array}{l}\text { Adapts the learning materials and incorporates EfS within formal } \\
\text { education system }\end{array}$ & 2015-present \\
\hline Zippora, female ultraorthodox & $\begin{array}{l}\text { Landscape architect of the municipality } \\
\text { Guest lecturer of science education in the local female } \\
\text { seminar-of-education }\end{array}$ & Landscape designer and professional consultation & 1990s-present \\
\hline \multicolumn{4}{|c|}{ Employees of Governmental Ministries } \\
\hline \multirow{3}{*}{ Naomi, female secular } & Regional EfS coordinator of the MoEP & & \\
\hline & $\begin{array}{l}\text { Previously affiliated with neighboring secular municipality which } \\
\text { provided EfS services to this municipality }\end{array}$ & $\begin{array}{l}\text { Responsible for the MoEP budget allocated to this municipality; provides } \\
\text { professional EE consultation. }\end{array}$ & 1994-2003 \\
\hline & Currently directly affiliated with this municipality & & 2003-present \\
\hline \multirow[b]{2}{*}{ Sarah, female secular } & $\begin{array}{l}\text { Previous EfS coordinator (position shared with a neighboring } \\
\text { secular municipality) }\end{array}$ & Responsible for all aspects of the EE activity conducted during that period & 2003-2009 \\
\hline & $\begin{array}{l}\text { Current director of a regional governmental EE center that provides } \\
\text { EE for local municipalities }\end{array}$ & $\begin{array}{l}\text { Responsible for policy and decisions concerning EfS (formal } \\
\text { and non-formal) }\end{array}$ & 2012-present \\
\hline Rachel, female ultraorthodox & $\begin{array}{l}\text { National and regional EfS instructor for the ultra- orthodox sector in } \\
\text { the MoE }\end{array}$ & $\begin{array}{l}\text { Professional assistance in incorporating national EE programs within the } \\
\text { education system }\end{array}$ & 2015-present \\
\hline \multicolumn{4}{|c|}{ Employees of EfS providers } \\
\hline Moishe, male ultraorthodox & $\begin{array}{l}\text { Chief executive officer of an ultraorthodox environmental NGO that } \\
\text { works with UGC }\end{array}$ & Involved in non-formal EfS & 2012-present \\
\hline Leah, female ultraorthodox & $\begin{array}{l}\text { Field trip guide in the ultraorthodox education system that provides } \\
\text { services to UGC }\end{array}$ & Involved in EfS integrated in field trips conducted with the schools & 2012-present \\
\hline
\end{tabular}


Table 2. Major Developments in Promoting EfS in UGC Municipality $\left(^{*}\right)$.

\begin{tabular}{|c|c|c|c|}
\hline Area & Focus of Action and/or Target Audience & $\begin{array}{l}\text { 2003-2010: } \\
\text { First Stage } \\
\text { (Before Establishment of Local Environmental Unit) }\end{array}$ & $\begin{array}{l}\text { 2011-Present: } \\
\text { Second Stage } \\
\text { (Since Establishment of the Local Environmental Unit) }\end{array}$ \\
\hline \multirow[b]{2}{*}{ Formal education } & Kindergartens & 20 female kindergartens & $>50$ female kindergartens (1750 pupils) \\
\hline & Schools & One female post-secondary education seminary & $\begin{array}{l}\sim 15 \text { female elementary schools ( }>5000 \text { pupils) } \\
20 \text { male Heders ( }>3000 \text { pupils) } \\
\text { one female education seminary (1200 students) }\end{array}$ \\
\hline Professional development in EfS & Short (one day) and extended programs & 20 pre-school educators & $\begin{array}{l}\sim 50 \text { pre-school educators } \\
\sim 200 \text { female elementary school educators } \\
>20 \text { male educators } \\
5 \text { municipal employees }\end{array}$ \\
\hline Non-formal education & $\begin{array}{l}\text { Community centers, neighborhoods; } \\
\text { intergenerational activities }\end{array}$ & $\begin{array}{l}\text { Limited educational activity conducted by a few NGOs } \\
\text { mainly for families }\end{array}$ & More extensive educational activities conducted by a larger number of $\mathrm{NGO}$ \\
\hline \multirow{2}{*}{$\begin{array}{l}\text { Connection to national EfS initiatives, } \\
\text { developments and programs }\end{array}$} & "Green-School Certification" & None & $\begin{array}{l}10 \text { female kindergartens } \\
\sim 5 \text { female elementary school }\end{array}$ \\
\hline & Government calls for educational proposals & Limited, sporadic (conducted by the joint EfS coordinator) & Response to ongoing calls on a regular basis \\
\hline \multirow{3}{*}{ Budget and manpower for EfS } & From the MoE & Limited budget, according to ad-hoc requests & National and regional EfS instructor provides services for the municipality \\
\hline & From the MoEP & $\begin{array}{l}\text { Regional coordinator provides services to the joint } \\
\text { EfS coordinator }\end{array}$ & EfS budget allocation is according to national calls and specific criteria \\
\hline & From the local municipality & Limited, for the joint EfS coordinator & $\begin{array}{l}\text { Pre-planned annual EfS budget; Appointment of specific municipal EfS } \\
\text { coordinator and assistance EfS coordinator }\end{array}$ \\
\hline
\end{tabular}

$\left(^{*}\right)$ Data provided by the municipality environmental unit (updated 2018). 
Table 3. Main Areas of EfS Activity Conducted by UGC Municipality (during the second stage).

\begin{tabular}{|c|c|c|}
\hline Area of Activity & Description of Activities & Contribution \\
\hline \multirow{6}{*}{$\begin{array}{l}\text { Adapting and developing UO-EfS curricula and } \\
\text { learning materials for schools }\end{array}$} & $\begin{array}{l}\text { Adapting principles and content of sustainability and EfS (according to national standards) into values, norms } \\
\text { and behaviors that fit the Jewish laws and UO culture }\end{array}$ & \multirow{5}{*}{$\begin{array}{l}\text { - Increases the number of formal education frameworks that } \\
\text { include EfS } \\
\text { - Exposes more students to principles of sustainability } \\
\text { - Legitimizes incorporation of sustainability issues within the } \\
\text { independent schools' UO curriculum } \\
\text { - Strengthens internship component of student-teachers' programs }\end{array}$} \\
\hline & $\begin{array}{l}\text { Consulting with EfS experts inside and outside the UO community concerning EfS content and ways of } \\
\text { visualizing this for UO }\end{array}$ & \\
\hline & $\begin{array}{l}\text { Obtaining approval (concerning educational content and its visualization) of UO religious authorities for use in } \\
\text { formal and non-formal education settings }\end{array}$ & \\
\hline & Collaborating with female seminaries in the development UO-EfS learning units & \\
\hline & Teacher involvement in developing EfS programs for UO kindergartens and schools & \\
\hline & Adapting existing media and campaigning material for UO schools and public & - Increases exposure of $\mathrm{UO}$ community to sustainability issues \\
\hline \multirow[b]{2}{*}{ Professional development } & Participation of the municipality administrators in academic and/or professional environmental studies & $\begin{array}{l}\text { - Improves environmental literacy of environmental leaders within } \\
\text { UGC municipality. }\end{array}$ \\
\hline & $\begin{array}{l}\text { Participation of UO kindergarten and school teachers in EfS workshops and professional } \\
\text { development programs }\end{array}$ & - Improves educators' capacity to conduct effective UO-EfS \\
\hline \multirow{3}{*}{$\begin{array}{l}\text { Strengthening interaction with government and } \\
\text { environmental NGOs }\end{array}$} & Regular participation in national government calls for embedding EfS in the local educational system & \multirow{3}{*}{$\begin{array}{l}\text { - Increases governmental support for EfS } \\
\text { - Raises awareness of environmental organizations to UO needs } \\
\text { concerning EfS } \\
\text { - Decreases stereotypical public perception regarding } \\
\text { environmentalism in the UO community }\end{array}$} \\
\hline & $\begin{array}{l}\text { Collaborating with environmental organizations in the implementation of national and local EfS initiatives in } \\
\text { UO schools and community }\end{array}$ & \\
\hline & Training EfS facilitators from non-ultra-orthodox NGOs to work with the local community & \\
\hline \multirow[t]{2}{*}{ Increasing participation of schools in EfS } & Recruiting headmasters of kindergartens and schools & $\begin{array}{l}\text { - Increases the number of formal education frameworks that } \\
\text { incorporate EfS. } \\
\text { - Exposes more students to principles of sustainability. }\end{array}$ \\
\hline & Allocating financial resources suitable for the size of the local schools and kindergartens & - Increases school and kindergarten involvement in EfS \\
\hline \multirow{5}{*}{$\begin{array}{l}\text { Involving the local UO community in non-formal } \\
\text { EfS initiatives and activities }\end{array}$} & Organizing place-based EfS activities and competitions for families around Jewish holidays & \multirow{5}{*}{$\begin{array}{l}\text { - Exposes male adults and children to EfS and involves them in it. } \\
\text { Encourages family involvement in EfS } \\
\text { Legitimizes including the environment and its protection as part o } \\
\text { UO daily life and behavior }\end{array}$} \\
\hline & Establishing and maintaining neighborhood community gardens & \\
\hline & Conducting evening lectures for the local public on environmental topics & \\
\hline & Obtaining active involvement and support of rabbis in promoting EfS within their community & \\
\hline & $\begin{array}{l}\text { Publishing popular articles, information and recommendations for families on environmental topics in local } \\
\text { papers and newsletters }\end{array}$ & \\
\hline
\end{tabular}


Analysis of the documents provided by interviewees enabled mapping the main stages, milestones, types of actions, target audiences and scope of EfS conducted by the municipality. This information also supplemented the data obtained from the interviews, validating specific actions conducted by the participants. Document analysis and validation were achieved through a process similar to that used for the interview analysis.

\section{Results and Discussion}

The results of this study are presented in two sections. The first section provides the context for exploring the developments conducted by the municipality regarding EfS within UGC community. It briefly outlines the major developments in environmental management promoted by the municipality, based on relevant documents and the interviews. The second section focuses on the developments conducted by UGC for bringing EfS into the local community. It is based mainly on the interviews conducted within the stakeholders from within UGC and from the external organizations. Together, the two sections address the research questions.

\subsection{Mapping the Environmental Developments and Actions within UGC Municipality}

From the analysis it became evident that incorporating sustainability within the city's management is divided into two periods:

Time period 2003-2010-This is the period prior to the establishment of an environmental department within UGC. During this time, environmental quality was addressed by a unit shared with neighboring secular municipalities. The UO representative in this joint unit was the mayor, and environmental quality issues were addressed under the departments of infrastructure and health. Environmental management conducted in UGC Municipality was limited to recycling beverage containers. According to the current head of the environmental department (Abraham), under such conditions, the services provided by this unit were unsuitable to the requirements of the UO community (e.g., insufficient number of waste separation containers in relation to the population size). Educational activity was conducted by a joint EfS coordinator (Sarah) and was limited to $\sim 20$ kindergartens ( $10 \%$ of the total number of kindergartens), one female seminary of education and some non-formal activities for both schools and the general public conducted by NGOs (Table 2). The main EfS activity in kindergartens focused on establishing school gardens. Sarah, Rebecca and Naomi all characterized this period as that in which the local school system (namely, the superintendents, supervisors and pre-school educators) was not yet prepared for including the environmental perspective. However, according to Sarah, the pre-school system was open to it and, among other things, conducted professional development programs for pre-school educators. Budget allocation for EfS was flexible and according to the ad-hoc requests from the field (as indicated by Rebecca and Naomi).

Time period 2011-present-The opportunity to establish an environmental department arose with the election of the new mayor, who realized that an independent environmental department is crucial for treating environmental issues effectively in a manner appropriate to the unique attributes of the UO community. This stage is characterized by a significant proliferation in environmental activity. According to the head of the environmental department within UGC (Abraham), environmental management has expanded into new areas: enforcing environmental standards in urban planning, industry and businesses; pollution monitoring; protecting local resources; mapping local urban biodiversity; addressing public inquiries and the development of EfS, all adapted specifically for the UO community. Table 2 maps the developments concerning EfS. A crucial element in this development was the appointment of an EfS coordinator (Rebecca) from within the local UO community. This enabled a systemic approach to promoting EfS, including budget allocation and recruitment; creating interactions with relevant government departments and connecting to national EfS initiatives and programs; adapting EfS curricula and educational materials to the UO community ("ultra-Orthodoxing"); implementing EfS into more school levels (mainly female) and taking steps to include male schools. This systemic approach increased the number of students exposed to this area of education; expanded 
professional teacher development; allowed for the professional development of (environmental) municipal employees; and broadened non-formal EfS by including richer content and adding more target audiences.

Transition from the first to second stage required establishing a suitable organizational culture in the new municipal environmental unit, necessary for fruitful cooperation between the local educational system and external regional and national organizations. All interviewees, both from UGC's environmental unit and the MoEP EfS coordinator, emphasized that in order to obtain government financial support, the adaptation and implementation of educational materials must meet national EfS standards. According to Sarah and Naomi, the efforts to adopt such a systemic, regulated and professional approach in the incorporation of environmental management and education within UGC's agenda were acknowledged by the MoEP. This was reflected in increased resources and flexibility in their allocation according to the specific needs of UO formal and non-formal education.

In the second period, EfS has expanded significantly on a number of fronts: (1) From the pre-school framework to elementary level (mainly girls' schools, and later to a few boys' schools). Within each, there has been an increase in the number of schools involved and, thus, students exposed to EfS (Table 2); (2) Local schools (first kindergartens and later, female elementary schools) have entered the national strategy of "Green School Certification (Green-school accreditation was initiated in 2004 by the MoEP, in cooperation with the MoE, as part of the national sustainable development strategy endorsed in 2003 (MoEP, 2003))"; (3) Non-formal, community frameworks have been established; (4) Educators and municipal employees have undergone professional development; and (5) Collaboration with GOs and NGOs has expanded significantly (elaborated on below).

\subsection{EfS Actions Implemented by the Municipality to Address Major Challenges}

Figure 1 outlines the framework of steps that were implemented to answer the research questions.

Analysis of the interviews revealed two major, related challenges that need to be addressed in the process of bringing EfS into the UO community: (1) Low levels of environmentalism and environmental literacy; (2) Religious and socio-cultural barriers (Figure 1). Concerning limited environmentalism, the administrators emphasized that the scientific and environmental knowledge of UO educators and students is low because of limited science education in the UO school and teacher training curricula. Rebecca added that her difficulty in finding both UO scientists and experts in environmental sciences or outside experts who are familiar with UO culture, limits her possibility to expand teachers' knowledge during professional development programs. Regarding the second challenge, the UO community is characterized by a stereotypical perception of the environment through the religious lens, and not through contemporary global, sustainability discourse. Along the same lines, they view non-religious related environmental activism as irrelevant. Moreover, if religious and environmental values contradict, abiding by halacha is always above the environment. Another culturally related challenge stems from the community's segregation by choice, which impedes interactions with external institutions and processes. It was evident from the interviews that these challenges provided the point of departure for all EfS-oriented activity and they revealed a diverse range of educational activities aimed at enhancing environmentalism within the local UO community (Table 3). The following subsections present the main themes elicited from our analysis.

\subsubsection{Adapting and Developing EfS Curricula and Learning Materials for Schools}

Selecting environmental topics for EfS in the UO community requires various considerations. The first is selecting subjects that do not contradict halacha and the UO interpretation of the Bible. A classical obstacle relates to Earth's age and "the creation". Zippora stated, "UO would not accept the idea that Earth exists for billions of years, since they believe and learn that Earth was created by God 5000 years ago". Adapting environmental content to specific values and norms that characterize this community is another challenge. An example addressed by Rebecca and Sima is waste, which the UO community perceives as "impure" and therefore not respectable for discussing in public. Thus, 
to incorporate such topics, it is necessary to provide them with added value that justifies addressing them in UO-EfS education curricula. As Sima stated, "We will not talk about [dirty] waste directly, but will approach the subject via 'recycling', which transforms a product into a valuable material from which we can create something new". Her example demonstrates how a "non-respectable" topic can be transformed into a legitimate one.

Rebecca demonstrated another innovative approach to adapting the subject of recycling for the UO community: "We identified that the concept 'recycling' relates to the halacha of 'Geniza' (Geniza (literally "storage")-The law that directs the special way of disposing religious items (no longer suitable for their use) in the designated storage area in the synagogue or cemetery). 'Geniza' implies both the commodity's end-of-life as well as the necessity for the physical space for its disposal. This provides a point of departure for thinking about alternatives to waste disposal". This nicely exemplifies how to use a common concept in the UO way of life and tie it in with the environmental context. It also demonstrates Rebecca's professional mastery of environmental content, which enables her to select diverse and creative topics and not only the conventional topics from Judaism that are typically affiliated with ecology, such as "Bal Tashchit" (Bal-tashchit (literally "do not destroy") - the Biblical law that forbids, in the context of wartime, cutting down fruit trees to assist siege, later broadened to prohibit needless destruction or waste.).

Introducing environmental content for educational purposes also requires adapting learning materials. In view of the limited number of UO environmental professionals, this task was conducted mainly by the UGC's educational unit. Rebecca provided examples of different institutions she works with for such adaptation, such as UO publicity and marketing companies and a local female education seminary. From the latter, she used educational materials developed by the students as part of their learning assignments and improved them for implementing in schools. During this process, she also worked with the MoEP EfS coordinator on the content. This example also demonstrates the types of interactions she has created between UGC's environmental unit and the secular world, which we elaborate on later.

A crucial component of adapting educational materials for UO schools' curricula is obtaining the approval of the religious authorities. Rebecca described this as a complex, time-consuming process, as it involves three different authorities: the general director of the independent education system, the rabbi who serves as the educational superintendent and the educational instructors who work with the schools, " . . each demanding its imprint on the final product and they don't always see things the same way". In view of this cumbersome process, a noteworthy example is the development of an educational unit focusing on individual behavior in commons, which deals with different religious virtues (midot tovot), and includes a student handbook adapted for use in the heder. This example ties in with the challenge of finding ways to incorporate environmental topics within formal male education. Even the title of the unit uses the Jewish term rashut harabim (the public domain) instead of the usual term the commons". In 2017, 3500 5th-6th grade boys studied the unit. Rebecca describes how every aspect of it is inherently UO:

... it was written and produced by a "hard core" UO educator who worked in the "heder"; this presents "ultraorthodoxing" at its utmost ... only such a person knows how to convey the content in a way that is acceptable in the "heder" without resistance ... this is the method to be used in the UO, the whole city is talking about it. "Rashut harabim" is a halachic term from the "Talmud", which we can relate to because we deeply understand what it means. Conversely, "the commons" is an expression unclear to us and therefore does not evoke the commitment of the UO society.

This example may be seen as one of the utmost achievements in incorporating environmental content within the UO school system and selecting those problems that comprise major environmental issues in this community, such as lack of awareness and care of the commons. It exemplifies how to select a classic sustainability issue (the commons), identify the most suitable parallel within Jewish halacha (rashut harabim), develop a complete de novo learning unit and materials on the topic and bring it into the hardly accessible all-male schools. 
With the aim of evoking the UO schools' and community's acceptance of environmental issues within the public agenda, it is necessary to use appropriate visual content in educational resources, media and campaigning material. Abraham described the process of developing a media character suitable for the UO community to be used for the ongoing recycling campaign, instead of the existing secular celebrity-based figure whose head was portrayed as a "grass head" for the green campaign:

We decided to create a unique character since the secular celebrity is inappropriate and our public doesn't understand the humor of how he is portrayed ... people would ask me, "What happened to his hair? Was he electrocuted?" We embedded the "Danny" [pseudonym] character into activities for children and schools; it's Danny who does the explaining to our children ... today anyone you ask recognizes Danny.

The creation of the Danny character exemplifies that parallel to selecting suitable content, it is also necessary to create suitable visuals according to the community's norms as part of "ultraorthodoxing" EfS.

\subsubsection{Professional Development}

Promoting EfS in the UO community necessitated the professional development of both the municipal staff and educators in the school system. This is all the more crucial since science education is limited in UO schools and teacher training. Rebecca herself acknowledged this: "I realized that I lacked professional knowledge, so I signed up for continuing studies in environmental education ... all my current environmental knowledge I attribute to my graduate studies which I conducted in a secular college of education". Both Abraham and Naomi agree that Rebecca's professional development proved to be a crucial factor in evoking the community's trust in her and accepting the new directions and content she incorporated. Since professional resources and environmental experts were non-existent within the UO society, all the professional staff in the environmental unit needed to conduct their professional development in non-UO frameworks, the majority of which are secular. Significantly, this process changed the typical alienated views towards environmentalism and environmental activism that some of the municipality staff had prior to these studies, as Abraham admitted: "Previously I viewed these 'green people' as interfering ... today I can appreciate protecting the environment and these people's work." This example demonstrates how gaining environmental knowledge changed stereotypical perceptions concerning environmentalism. This conceptual change is necessary for stakeholders whose function it is to promote sustainability within their community. All the interviewees emphasized that the professional development of pre-school and school teachers and the development of their environmental literacy made a significant contribution to promoting EfS.

\subsubsection{Strengthening Interaction between the Government and Environmental NGOs}

A crucial factor in UGC's success in promoting EfS is the understanding that collaborating and networking with the government and non-religious NGOs is necessary at various levels - for financial support and for reducing the cultural barriers that lead the different sides to perceive environment and its protection differently. Abraham, as head of the unit, identified Rebecca's professional and personal capacities to bridge these gaps. Rebecca explained:

Abraham told me: you are good at the interface between our municipality and governmental bodies such as the MoEP, so try to think how to take advantage of this ... I implemented my capacity to respectfully and professionally represent the UO sector to the MoEP, which is important since the general public lacks a proper perspective of our sector.

The achievements of UGC's efforts are reinforced by external stakeholders, such as Naomi and Sarah. In Naomi's description of how her work with the municipality developed and evolved, she explained that obtaining formal (financial) support from the MoEP requires that the educational activities conducted by the municipality align with MoEP guidelines and regulations. Despite this, in 
the initial stages, she was lenient about it, understanding that change take time and for such a change to occur, national support is crucial. To exemplify this, she commented that in the first EfS-oriented Hannukah event for UO families, the volume of activities not directly related to the environment was large. By the second event, which was totally organized by the municipality (Rebecca), and despite the fact that the MoEP still did not finance it, the main focus of all the activities was environmental, aligning with MoEP standards. This emphasizes that the flexible approach demonstrated by the MoEP EfS coordinator proved to be an effective strategy, as Naomi herself acknowledged.

Regarding financial support, all UGC interviewees stated that the establishment of the environmental unit enabled the submission for significantly increased financial support via regular MoEP channels. Naomi emphasized the MoEP's positive attitude towards these efforts, which they supported by allocating budgets utilizing the preferences that exist within the national criteria for low socioeconomic sectors. Another aspect indicated by both Rebecca and Naomi was the need to adapt the MoEP budget to the extremely large number of students that characterizes the UO schools. Naomi admitted that she was unaware of this when she first provided financial support, but resulting from productive interaction with Rebecca, later adapted financing according to the needs. She specifically expressed her satisfaction regarding how these funds are effectively and creatively utilized, such as for adapting MoEP's environmental campaigns and all other educational materials for use in UO-EfS. Naomi's perspective is that the UGC's environmental unit is an inspiring model: "Rebecca is widely acknowledged in Israel-she is the figure people turn to for consultation concerning education within the UO community. We [the MoEP] try and spread the work achieved in this municipality to other cities". Her words attest to the success achieved in establishing mutual trust in order to establish a fruitful collaboration.

Despite these significant advances in interactions between UGC municipality and external institutions, much room remains for expanding the adaptation of campaigns and publicity, as well as educational materials prepared by these organizations for the needs of the UO society.

\subsubsection{Increasing School Participation in EfS}

Increasing school involvement in EfS is largely dependent on the openness, interest and commitment of the kindergarten and school headmasters. Rebecca demonstrated her strategy to encourage schools to include EfS in their curricula: "First, I presented this as a bonus-you have been chosen by the municipality and the superintendent of the educational system, including a financial bonus. When presented as such, the headmasters could not refuse". Financing the schools' involvement in EfS is no small feat due to the extremely large number of students, and requires sufficient funding, as discussed above. Other interviewees supported the notion that once involved in EfS, kindergartens and elementary schools usually demonstrated increased interest and engagement in sustainability, and often responded positively to Rebecca's suggestion that they enter the national program for"green school certification" (Table 2).

Concerning the limited opportunities to expose male school students to EfS, UGC's educational unit has developed ways of including EE within the given boundaries. For example, including boys in environmental activities within the non-formal framework of youth movements, or bringing extra-curricular environmental activities into boys' schools, such as introducing recycling to school management. Notwithstanding these initial steps, significant change will require ongoing efforts.

\subsubsection{Involving the Local Community in Non-Formal EfS Initiatives and Activities}

A significant challenge for UGC's educational unit is creating environmental awareness within the local UO community, which requires taking into consideration the unique lifestyle that characterizes this sector, for example the halachic daily rituals, and the traditionally large family structure, with the women taking on the majority of household responsibilities. One strategy used to increase the involvement of the local community was to design family-oriented, environmental enrichment activities, focusing on mothers and children. The goal was to design activities that are suitable and meaningful for both adults and children. Jewish holidays were chosen as a frame for this educational avenue for two reasons: they are logistically practical since schools are on vacation and, 
more importantly, they enable addressing the environment and human nature relationships from the religious perspective, which renders it meaningful for this audience. Holidays that are commonly used as a platform for addressing ecological-environmental aspects beyond the direct religious dimension are Hannukah, Tu-B'Shvat (the holiday of the trees, which provides the opportunity to learn about the importance of trees in nature) and Lag B'Omer. The latter provides a good example of how Rebecca incorporated environmental quality issues aimed at changing deeply-rooted customs. The tradition of this holiday is to light bonfires, and Rebecca's aim was to reduce the significant air pollution caused by this holiday by educating the local population. (Air quality monitoring conducted by the MoEP reports increased levels of particulate matter pollution immediately following this night, grounding the environmental consequences of this tradition.) Toward this end, she implemented diverse means, including: creating a public campaign that connects bonfire sourced air pollution to health consequences; positive incentives (rewards) to motivate children to bring dangerous flammable materials to a collection point; and recruiting the local fire department to conduct open-house events to explain the dangers of bonfires to the public. Finally, she offered an alternative event in the city center in which a huge electric candelabra was lit (instead of a bonfire) by children pedaling bicycles. To preserve the holiday's mitzva, an olive oil candle was also lit. The multi-perspective tactics Rebecca employed demonstrate the systemic approach of the municipal unit for UO-EfS: "We enacted the holiday tradition, reduced the number of bonfires in the city by 50 percent, and the bonfires that were lit were fed by safe materials. This was a huge success." (Rebecca).

Another significant tool for connecting the community to the environment is through establishing and maintaining neighborhood community gardens. As described by Abraham:

... We established a community garden in a low socioeconomic status neighborhood that suffers from local vandalism, by engaging the residents in the activity. Rebecca presented them with the principles of vertical gardening. The response was great, and since this garden is highly visible in the neighborhood, we've received a lot of positive feedback and this has increased the interest of the local community, which we hope will lead to increased involvement in other local activities.

As an outsider of this community, Naomi added an interesting viewpoint regarding the benefits of the gardens for the community:

Both children and adults get a lot of pleasure from maintaining such gardens; they raise halacha-related questions around gardening, such as growing plants during the shmita (Shmita literally means "release")- the 7th year of the agricultural cycle determined by the Tora, plots lie fallow but are maintained (watering, weeding, trimming, etc.) to let the soil replenish) year ... such interest cannot be taken for granted since this community normally gathers in the synagogue [around religious topics] and not around non-religious topics.

This activity illustrates how a sustainability-based community activity provides several benefits. It enriches the public's awareness of topics and issues that are part of the current social agenda (i.e., community gardens), while linking this public to the religious topics which interest them. Furthermore, it strengthens the community's "place attachment", which reduces the vandalism of facilities that the municipality has invested in (e.g., playgrounds). This, in turn, contributes to the municipality's efforts in revamping these neighborhoods. Additionally, it exemplifies collaborative work with different departments in the municipality (e.g., welfare, engineering and environmental quality). From the EfS perspective, it demonstrates both improving the community's care for their public sphere (the commons) and enriching the collective identity using non-religious content (elaborated on later).

Abraham revealed additional directions for involving the local community in sustainability discourse by conducting open lectures for the public and arranging professional lectures for municipality workers, often under the title of "environment from the perspective of Judaism". He also stated that a key to encouraging the local community to accept the environment as a "legitimate" area, and adopting more sustainability-based principles in their daily lives, is by including well-known and 
esteemed rabbis in local campaigns to support the messages the media are conveying, and inviting them to public activities and municipal meetings.

\subsection{Ongoing Challenges}

Despite the significant advances that have been made in bringing the subject of the environment into this community, as presented above, this is a work-in-process and much room remains for expanding and deepening these achievements. In addition, we identified several specific areas that are especially challenging as they deal with deeply rooted cultural habits and attitudes. Table 4 maps these major ongoing challenges and presents exemplar citations.

Regarding the first area (increasing this community's EL), abiding by the Jewish halacha in daily life, even when this reflects pro-environmental behavior, is always from a religious perspective rather than an environmental perspective. For example, the issue of the commons, specifically in the context of maintaining cleanliness, was a recurring theme in all the interviews. Another aspect of this community's lack of environmental awareness relates to connectedness to (urban) nature. Zippora expressed her frustration that although the Jewish mitzvas are connected to nature, in reality this community lacks nature-attachment, including urban nature, and also has a fear of pets. Other interviewees also acknowledged that nature remains an alien area, especially for boys, who spend most of their time indoors studying Tora in the heder.

Regarding religious and socio-cultural barriers, most of the interviewees emphasized that conducting religious mitzvas is always above everything else, so in situations in which there is a conflict of religious and environmental values, religion always takes priority over the environment. When asked to suggest how they could mitigate this conflict, they avoided giving a direct answer, reflected in Zippora's response (Table 4), which illustrates that there are practical solutions, although she admits these are not always chosen.

A significant challenge raised by all interviewees is that, while substantial progress has been made in incorporating EfS within the female educational system, it is still minimal in the male system. In the male school curriculum, religious studies are strictly dominant with marginal room for other subjects, especially in secondary education (yeshiva). This impedes the possibility of incorporating environmental studies. Despite initial efforts to bring EfS into male education (Section 3.2.1), any significant change will require creative solutions that avoid clashing with religious studies. Regarding the barriers oriented in gender separation, all the women affiliated with UGC agreed that despite their crucial function in promoting EfS within the UO community, as females their personal involvement is limited in situations that require them to interact directly with men. These strict conditions complicate female involvement in male education frameworks.

While the UO society is perceived by the general public as a homogenous group, it is actually comprised of "streams" (i.e., rabbinical courts) that differ from each other. This presents a significant challenge, since there is no one suitable way of "ultraorthodoxing" EfS, which was the consensus among the participants. The strategy undertaken by the municipality was to align all EfS developments and adaptations according to the strictest stream and work with them, on the assumption that what is suitable for the strictest stream will also be appropriate for the less strict ones. Although this strategy has contributed to entering into the local education system, there remain many UO streams that are not exposed to EfS. 
Table 4. Ongoing challenges.

Area

Addressing the commons

\section{Raising attachment to local urban nature}

Exemplar Citations

Low Environmental Literacy of the Ultra-Orthodox Community

We need to promote cleanliness because it demonstrates just how much the UO society lags behind in environmental aspects. The first thing to focus on is taking responsibility for the commons. How can we convince people to make the effort to bring beverage containers to recycling bins if they don't see any problem with throwing them in the street? (Moishe)

.. We must incorporate the topic of urban nature, maybe via the Jewish verse: "How great are Your works, Hashem ... " (Psalms You don't have to know the birds' names, but you should notice that they are beautiful and they are around us. (Zippora)

Religious and socio-cultural barriers

Strengthening understanding that religion and environmental responsibility are not incompatible

Increasing EfS within the male educational system

... At the Sukkot holiday, the Tora commands us to cut off a palm frond from its tree-an anti-environmental action. It cuts the for mitzva observance ... we can always leave one frond on the tree to keep it alive, but this is not part of the mitzva (Zippora) The ideas of sustainability are written in the Tora, but in the yeshiva you can't address them explicitly; your focus is on studying the Tora ... [In boys-schools] it's impossible to replace a Tora class with an environmental education class; religious values are considered more important than environmental ones. (Abraham)

Gender separation limits the involvement of female professionals in EfS activities with male populatio Since I $\mathrm{m}$ a female $\mathrm{h}$ have to recruit a male project coordinator who will represent my professional role in the boys' schools, I find this very hard both as a woman and as EfS professional. (Rebbeca)

The mainstream of the ultra-orthodox community in our city is the "Litai" public. I needed to decide with which stream to start working, since what is suitable for one stream is not necessarily suitable for others ... currently I work only with the Litais, and have not yet expanded to others despite their interest. (Rebbeca)

Diversity within the ultra-orthodox society

When you say "green" to ultraorthodox people, they look at you strangely and send you back to speak with secular people from rich neighborhoods ... they view the "greenies" as the city's crazy people who resist any human development. (Abraham)

Misperceptions of the general public towards the UO, and vice versa concerning environmentalism 
Another major challenge relates to mutual stereotypical perceptions. While, in reality, the average ecological footprint of the UO is low, mainly due to their generally lower socioeconomic-status compared to other Jewish social groups in Israel [34], the general public views the UO as a non-environmental community. A major reason for this is the rundown and neglected surroundings that typically characterize UO neighborhoods, which reflect lack of care for the commons, or the notion that actions that are not "halacha-oriented are "unimportant", as explained above. The UO also hold stereotypical perceptions regarding environmentalism. They view themselves as environmentally friendly, due both to their modest lifestyle as well as to the environmentally responsible aspects embodied in many of the mitzvas. In parallel, they also view explicit involvement in pro-environmental actions as a non-religious "waste of time" and a "luxury" of the affluent secular community, and therefore not representative of their culture. They view environmental activity as extreme and odd, and irrelevant to them. This current situation of two-way stereotypical views hinders collaboration between the UO and the wider public and environmental organizations in terms of promoting the environment and embedding EfS into the UO community.

\section{General Discussion}

This study explored a pioneering municipal process of incorporating sustainability within an urban UO community via formal and non-formal education settings. The point-of-departure is that in multicultural societies, it is necessary to involve the diverse cultural groups in sustainability discourse toward developing their awareness, including environmental considerations in their daily lives and their engagement in decision-making processes. The discussion is organized around several themes elicited from the findings, and provides insights that may be applicable to other multicultural societies and settings worldwide.

\subsection{Top-Down and Systemic Approach and Process}

Environmental initiatives are commonly grass root, bottom-up processes [47]. The chances of such initiatives impacting society and sustaining themselves in the long run is largely dependent on top-down support, and when this does not occur, such initiatives often dwindle because of the burnout of those few highly dedicated individuals. In this case, comprehension of this issue in UGC was crucial because it led the local decision-makers to establish a top-down strategy, reflected in several aspects: primarily, establishing an environmental department within the municipality to cope with environmental challenges in ways suitable to the unique characteristics of the UO community. Another crucial component was establishing new key positions (e.g., an EfS coordinator) and staffing them with people selected from within the UO community (elaborated on later). This provided the community with formal figures responsible for all aspects related to promoting EfS within the city and to whom the citizens can turn in connection to EfS. In this case, the top-down policy led to a systemic approach because it enabled mapping the local needs and prioritizing them, allocating resources (financial and human) and distributing them according to priorities, designing suitable educational programs and generating professional networking within the municipality and with external institutions. It is widely agreed in the literature that addressing environmental challenges, due to their complexity, multi-dimensionality, and multiple and often opposing stakeholders, requires a systemic approach $[4,48]$. In the context of UGC, applying a systemic approach proved effective, as demonstrated by the many developments achieved in a relatively short period (Sections 3.1 and 3.2).

\subsection{Developing Local Leaders and Agents-of-Change}

The municipal stakeholders that participated in this study can be viewed as leaders and change agents in their society, since they instigate changes in the way of thinking and actions that are not inherent in the discourse of the UO society. It is especially significant that this leadership developed from within the UO community. In order to promote social transformation, Ziekerman and Kahaner [49] have also identified establishing influential political and social leadership from 
within the particular community as crucial in relation to the UO society in Israel. Experience gained worldwide supports the notion that promoting change within specific cultural groups is more successful when achieved by creating leadership from within the community and training them for their role, as opposed to bringing in specialists from outside the community [50,51]. In this study, just the establishment of the environmental unit (Section 3.1) and filling the new positions with UO staff enabled, in itself, the adaption of EfS according to the society's religious laws, values, ideas and traditions. This proved to be an effective strategy as both participants from UGC and from external institutions confirmed (Section 3.2). Another important factor was the professional development the local staff undertook. This enabled them to combine the environmental content proficiency gained outside the UO world with inside understanding of the UO culture. This was evident, for example, from their capacity to "translate" ("ultraorthodoxing") environmental topics into UO "language". Thus, their approach reflects two important principles: the local leadership's recognition of the importance of EfS and its promotion within the UO community, despite the fact that environment is foreign to this community; and second, recognition of the necessity to cultivate local educational leadership from within the community.

These phenomena tie this study into the area of 'social capital'. According to Putnam [52], social capital is defined as "features of social organization such as networks, norms and social trust that facilitate coordination and cooperation for mutual benefit". The establishment of the local municipal leadership from within the UO society, as well as its professional development, provide the conditions that facilitated the social trust of the UO community in their leaders. The "ultraorthodoxing" of environmental content that these local leaders undertook reflects addressing this subject in ways that are aligned and compatible with the religious and cultural norms of their community. The cooperation and collaboration with various figures in the UO community (e.g., Rabbis, schools, local experts, religious media figures) in the promotion of EfS within the community reflect their understanding that networking within the community is necessary to bring about the social change. This reflects the network aspect of creating 'social capital'. According to Putnam's [52] distinction between "bonding" (the networking within the social group) and "bridging" (the networking with individuals outside the social group), this internal networking reflects "bonding". Creating 'social capital' is acknowledged as a necessary component of sustainable community development [53] elaborated further on.

\subsection{Connecting Religion and Environment}

The findings indicate that the most effective way to connect the UO community to the ideas around environment and EfS is to work via their religious laws, which provide the moral and practical frames that guide their behavioral decisions in every aspect of their daily lives. The municipality's approach to bring in sustainability reflects the comprehension that individual environmental responsibility is not in conflict with religious commitment. From the perspective of local governance, UGC's strategy represents a novel management approach. Some research (for example $[28,54]$ ) recommends connecting EE to the individual's existing religious ideas and values as an approach to making it personally relevant. Given that in many religions, religious ideas are consistent with environmental values, environmental researchers and educators recommend utilizing religious values and traditions in EfS as a way to increase ecological awareness and promote environmental citizenship. Based on this idea and our findings, we claim that this may also be practical in the context of the UO society, by connecting ideas and principles of sustainability to the pre-existing religious values and beliefs of this society. Moreover, even if many aspects of their lifestyle are already environmentally sustainable due to their adherence to halacha (e.g., leading a modest life) and not from environmental considerations, it is essential to make the environmental perspective explicit as part of increasing their environmental awareness and citizenship. This approach aligns with the principles of MEE that advocate adapting education to specific cultural attributes and needs [30,32], and this is elaborated on below. 


\subsection{Bilateral Relationships (UO Community—Outside Institutions)}

The findings indicate that productive partnerships were established between the UO municipality and relevant external government and NGO environmental or educational organizations. Furthermore, it is evident from both the UO leaders and their counterparts from the external institutions that establishing these partnerships proved to be a crucial component in the success of the process of bringing in EfS to the UO community. From the UGC Municipality's perspective, these partnerships were fundamental in gaining the recognition of the external organizations that the UO community has particular characteristics that require a unique response with regard to incorporating EfS. This understanding enabled suitable support in terms of content, finances and logistics. From the perspective of the external organizations, creating partnerships proved an essential factor in building the mutual trust that led to more flexibility in the formal government support provided to the UO community (e.g., increased financial support for schools based on the large student body). Notably, this flexibility did not compromise the necessity of meeting the national standards for supporting UO-EfS. The broader insight is that creating partnerships is crucial, especially when working with segregated communities. This ties into the challenge of including and engaging minority groups in public discourse concerning the environment $[8,9,15]$.

Such inclusion is both conceptual and practical. Conceptually, it requires connecting these social groups to the idea at stake (i.e., environment and EfS), as addressed in previous themes. Practically, it entails building the interface to enable this to happen. The mutual partnerships created between the local governance (in this case, UGC) and the national government institutions reflect such an interface and provide a significant advantage: they enable the minority group to take part in public discourse and national processes without compromising its cultural values, norms and traditions. The above described phenomena align well with the "bridging" variant of 'social capital' defined by Putman [52], as well as the vertical networking described by Dale and Newman [53] who tie 'social capital' to sustainable community development. According to Dale and Newman, a necessary component of such development is collaboration between local governmental leadership and other government levels as well as civil society organizations. They claim and demonstrate that partnerships between vertical government levels is necessary for accessing resources and obtaining decision-makers' support. The successful creation of networking with external government and non-government bodies found in this study exemplifies this. Creating the mutual trust and partnerships between the local (i.e., municipal government) and the national governmental level (i.e., MoEP) enabled access to external financial resources. Additionally, it created the trust that led the government (MoEP) to more flexibility, adapting its policy to the requirements of the local (UO) community. According to Dale and Newman [53], government policy is a complementary component to social capital toward achieving sustainable community development. This "bridging" and "vertical" networking led by UGC leadership may be seen as a step in the direction of including the UO community within the processes of policy-making in broader society. The process that this UO community is undergoing may be applicable in other multicultural settings with segregated and/or minority groups.

\section{Conclusions}

With regard to multicultural education, scholars identify two approaches-pluralistic and particularistic [33,37]. Based on this study's findings, we suggest adopting the particularistic approach, as a crucially required initial stage in the long-term process of including different social groups within the broader pluralistic dialogue [55]. In such a process, the particularistic approach has several advantages in promoting EfS within culturally diverse groups of multicultural societies: it may enable cultural groups to identify with ideas concerning environment and sustainability by illuminating the linkage of the environment to the cultural values and ideas inherent in the specific group. This may create emotional attachment to the area of environment, and in this way may lower the resistance to bringing EfS into such groups. Since introducing new ideas often encounters resistance, lowering resistance is especially crucial in the initial stages of such processes of change. Additionally, in the 
context of EfS, it is uncontested in the literature that in enabling and promoting behavioral change, the affective dimension is no less important than the cognitive dimension [56,57]. The particularistic approach is specifically relevant in the environmental arena, because it provides an opportunity for culturally diverse groups (including minority groups) to take part in public discourse and national processes without compromising their cultural values, norms and traditions. This is in keeping with the idea that MEE emphasizes: " ... increased access of culturally diverse, not only the dominant, groups to environmental education and increased representation of their worldviews in it" ([30], p. 28).

Implementing the particularistic approach within specific communities (such as the UO) provides the means for empowering these communities, and such empowerment is a necessary step towards the participation of such cultural groups in the pluralistic dialogue. Thus, we view the particularistic approach not as the endpoint, which risks leading to a separatist society (which is currently the case of the majority of the segregated UO community), rather as a first and necessary step in the process towards a multicultural society that acknowledges and embraces equality and cultural diversity [38]. Current developments within the UO society in Israel indicate the timeliness of such a process: despite that the Israeli UO are segregated-by-choice, recently this society is experiencing a change in which UO individuals are becoming more involved in institutions and processes of the wider Israeli society (e.g., higher education, workplace, military service) without compromising the religious and cultural values [58]. This provides evidence that the process of their inclusion in the wider pluralistic dialogue is underway, thus reinforcing the necessity that this process includes the environmental arena. The strategy of starting with the particularistic approach, evolving later into a more pluralistic approach (without compromising value and attributes of a specific cultural group) may be applicable in other similar settings.

From this study, it is possible to elicit several circumstances that may facilitate incorporating EfS within multicultural settings beyond the context of this study: (1) Allocating and cultivating change-agents who are leaders from within the cultural group in which the environment and EfS is to be introduced; (2) Building mutual trust between leaders of the specific cultural group and external stakeholders and policy-makers (e.g., governmental organizations). This may lead to openness to different perspectives and flexibility, which strengthen collaboration. This direction is also suggested by Gal [58]; (3) Thinking creatively to find ways to change culturally embedded, stereotypical perceptions regarding environmental behavior, and illustrating how environmental notions and responsibilities do not clash with specific cultural values; and (4) Establishing ongoing support for the local change agents, in view of the lengthiness of creating social change, to enable ongoing maintenance of the process.

As discussed above, this study also ties into the area of developing 'social capital'. A limitation is that, in the context of social capital, this study focused on the community's leaders, who are a crucial part of a community's social capital, but it did not explore the perspective of the citizens. Thus, a pertinent direction for further research would be to investigate the process this UO community is experiencing from the civilians' point of view. Additionally, since this process of social change is long-term, it is worthwhile to investigate its ongoing developments. While the interviews may have not addressed all aspects of the multifaceted work promoted by the participants, it is evident that this pioneering city is laying the grounds for including other marginalized communities, as well, in environmental discourse in the broader society.

Author Contributions: I.A. and G.S. developed the interview protocol. I.A., G.S. and D.G. collected the data. I.A. and D.G. conducted analysis of the data, interpreted the findings and wrote the paper, working equally on this article as first authors. G.S. also contributed in initial stages of data analysis and in collection of background material.

Funding: This research received no external funding.

Acknowledgments: The authors thank the interviewees for their agreement to take part in this study and for the rich data they provided. Kibbutzim College of Education Technology and the Arts is thanked for its financial support for the editing process.

Conflicts of Interest: The authors declare no conflict of interest. 


\section{References}

1. Central Bureau of Statistics. Population. Available online: http://www.cbs.gov.il/publications18/ yarhon0718/pdf/b1.pdf (accessed on 16 August 2018).

2. UNESCO. Transforming Our World: The 2030 Agenda for Sustainable Development. 2015. Available online: https://sustainabledevelopment.un.org/content/documents/21252030\%20Agenda\% 20for\%20Sustainable\%20Development\%20web.pdf (accessed on 16 August 2018).

3. Soini, K.; Birkeland, I. Exploring the scientific discourse on cultural sustainability. Geoforum 2014, 51, $213-223$. [CrossRef]

4. Capra, F. A New Scientific Understanding of Living Systems: The Web of Life; Bandway: NY, New York, USA, 1996; ISBN 978-0385476768.

5. North American Association for Environmental Education (NAAEE). Excellence in Environmental Education: Guidelines for Learning (K-12). 2010. Available online: http:/ / resources.spaces3.com/89c197bf-e630-42b0ad9a-91f0bc55c72d.pdf (accessed on 10 October 2018).

6. UNESCO. Cultural Diversity and Biodiversity for Sustainable Development. 2002. Available online: http:/ / unesdoc.unesco.org/images/0013/001322/132262e.pdf (accessed on 16 August 2018).

7. Agyeman, J. Culturing environmental education: From first nation to frustration. Can. J. Environ. Educ. 2002, 7, 5-12.

8. Bianchini, J.A.; Akerson, V.L.; Calabrese Barton, A.; Lee, O.; Rodriguez, A.J. (Eds.) Moving the Equity Agenda Forward: Equity Research, Practice, and Policy in Science Education Vol. 5; Springer: Dordrecht, The Netherlands, 2012; ISBN 978-94-007-4467-7.

9. Rodriguez, A.J.; Lee, O. Culture and context. In Moving the Equity Agenda Forward: Equity Research, Practice, and Policy in Science Education; Bianchini, J.A., Akerson, V.L., Calabrese Barton, A., Lee, O., Rodriguez, A.J., Eds.; Springer: Dordrecht, The Netherlands, 2012; pp. 127-129. ISBN 978-94-007-4467-7.

10. Alkaher, I.; Tal, T. Environmental projects of Jewish and Arab youth in Israel: The adult leaders' views. Environ. Educ. Res. 2011, 17, 235-259. [CrossRef]

11. UNESCO. Education for Sustainability_From Rio to Johannesburg: Lessons Learnt from a Decade of Commitment; UNESCO: Paris, France, 2002.

12. McKeown, R.; Hopkins, C. EE $\neq$ ESD: Defusing the worry. Environ. Educ. Res. 2003, 9, 117-128. [CrossRef]

13. Gough, A. A rhetoric-practice gap: The DESD agenda and sustainable schools. Paper presented at the 10th APEID International Conference on 'Learning Together for Tomorrow', Bangkok, Thailand, 6-9 December 2006.

14. Tal, A. Pollution in a Promised Land: An Environmental History of Israel; University of California Press: Berkeley, CA, USA, 2002; ISBN 9780520234284.

15. Negev, M.; Garb, Y. Toward multicultural environmental education: The case of the Arab and ultraorthodox sectors in Israel. J. Environ. Educ. 2014, 45, 143-162. [CrossRef]

16. Schiffer, V. The Haredi Education System-Allocation, Regulation and Control; The Floersheimter Institute for Policy Studies: Jerusalem, Israel, 1998. (In Hebrew)

17. Comenetz, J. Census-based estimation of the Hasidic Jewish population. Contemp. Jewry 2006, 26, 35-74. [CrossRef]

18. Malach, G.; Choshen, M.; Cahaner, L. The Yearbook of Ultra-Orthodox Society in Israel. 2016. Available online: https:/ / www.idi.org.il/media/7882/haredi_shnaton.pdf (accessed on 1 February 2018). (In Hebrew)

19. Neria Ben-Shachar, R. To be the wife of a Talmid Hacham-How the socio-economic reality of the 'learners community' is perceived in the eyes of the Haredi women. Inquiry Haredi Soc. 2015, 2, 169-192. (In Hebrew)

20. Shilhav, Y. Ultraorthodox women-Between two worlds. Mifneh 2005, 46-47, 53-55. (In Hebrew)

21. Stadler, N. Yeshiva Fundamentalism: Piety, Gender, and Resistance in the Ultra-Orthodox World; NYU Press: New York, NY, USA, 2009; ISBN 9780814740491.

22. Gal, R. Ultra-Orthodox ('Haredi') Jews in Israel's Society: A 2014 Status Report. 2014, Haifa Israel: Samuel Neaman Institute. Available online: https:/ / www.neaman.org.il/EN/Ultra-Orthodox-Jews-Il-Society-2014Report (accessed on 10 August 2018). 
23. Garb, Y. Population Dynamics and Sustainability in the Israeli Context. Paths to Sustainability: Shadow Report to the Government of Israel's Assessment of Progress in Implementing Agenda. In Proceedings of the World Summit for Sustainable Development Johannesburg, Johannesburg, South Africa, 26 August-4 September 2002.

24. Feniger, Y.; Shavit, Y.; Ayalon, H. Religiosity, Reading and Educational Achievement among Jewish Students in Israel. Int. J. Jewish Educ. Res. 2014, 7, 29-67.

25. Benstein, J. The Way into Judaism and the Environment; Jewish Lights Publishing: Woodstock, VT, USA, 2006; ISBN 9781580232685.

26. Vogel, D. How green is Judaism? Exploring Jewish environmental ethics. Bus. Ethics Q. 2001, $349-363$. [CrossRef]

27. Gerstenfeld, M. The Environment in the Jewish Tradition: A Sustainable World; Research Series No 4; The Jerusalem Institute for Israel Studies, The Center for Environmental Policy: Jerusalem, Israel, 2002.

28. Hitzhusen, G. Religion and environmental education: Building on common ground. Can. J. Environ. Educ. 2002, 11, 9-25.

29. Shilhav, Y.; Kaplan, M. The Haredi Community and Environmental Quality; The Jerusalem Institute for Israel Studies: Jerusalem, Israel, 2003. (In Hebrew)

30. Marouli, C. Multicultural environmental education: Theory and practice. Can. J. Environ. Educ. 2002, 7, 26-42.

31. UNESCO. Learning to Live Together. Multiculturalism, 2017. Available online: http://www.unesco. $\mathrm{org} /$ new/en/social-and-human-sciences / themes/international-migration/glossary/multiculturalism/ (accessed on 2 June 2018).

32. Nordström, H.K. Environmental education and multicultural education-Too close to be separate? Int. Res. Geogr. Environ. Educ. 2008, 17, 131-145. [CrossRef]

33. Ravitch, D. Multiculturalism: E pluribus plures. Am. Sch. 1990, 59, 337-354.

34. Banks, J.A. Cultural Diversity and Education, 5th ed.; Routledge: New York, NY, USA, 2015; ISBN 9781317222460.

35. Asante, M.K. The Afrocentric idea in education. J. Negro Educ. 1991, 60, 170-180. [CrossRef]

36. Nieto, S. Critical multicultural education and students' perspectives. In The RoutledgeFalmer Reader in Multicultural Education; RoutledgeFalmer: London, UK, 2004; pp. 179-200.

37. Yona, Y. In Virtue of Difference: The Multicultural Project in Israel; Van Leer Institute: Jerusalem, Israel, 2005. (In Hebrew)

38. Vasta, E. Accommodating Diversity: Why Current Critiques of Multiculturalism Miss the Point? Working Paper No. 53; Centre of Immigration, Policy and Society, Univeristy of Oxford: Oxford, UK, 2007.

39. Blanchet-Cohen, N.; Reilly, R.C. Teachers' perspectives on environmental education in multicultural contexts: Towards culturally-responsive environmental education. Teach. Teach. Educ. 2013, 36, 12-22. [CrossRef]

40. Leeman, Y.; Pels, T. Citizenship education in the Dutch Multiethnic context. Eur. Educ. 2006, 38, 64-75. [CrossRef]

41. Alkaher, I.; Tal, T. The impact of socio-environmental projects of Jewish and Bedouin youth in Israel on students' local knowledge and views of each other. Inter. J. Sci. Educ. 2014, 36, 355-381. [CrossRef]

42. Tal, T.; Alkaher, I. Collaborative environmental projects in a multicultural society: Working from within separate or mutual landscapes? Cult. Stud. Sci. Educ. 2010, 5, 325-349. [CrossRef]

43. Richardson, T.A. At the garden agte: Community building through food: Revisiting the critique of "food, folk and fun" in multicultural education. Urban Rev. 2011, 43, 107-123. [CrossRef]

44. Cutter-Mackenzie, A. Multicultural school gardens: Creating engaging garden spaces in learning about language, culture, and environment. Can. J. Environ. Educ. 2009, 14, 122-135.

45. Strauss, A.; Corbin, J. Grounded theory methodology-An overview. In Handbook of Qualitative Research; Norman, K.D., Vannaeds, S.L.Y., Eds.; Sage Publications: Thousand Oaks, CA, USA, 1994; pp. 273-285.

46. Creswell, J.W.; Creswell, J.D. Research Design: Qualitative, Quantitative, and Mixed Methods Approaches; Sage Publications: New York, NY, USA, 2017.

47. Dharam, G.; Vivian, J.M. Grassroots Environmental Action: People's Participation in Sustainable Development; Routledge: New York, NY, USA, 2014; ISBN 0-415-07762-1.

48. Virapongse, A.; Brooks, S.; Covelli Metcalf, E.; Zedalis, M.; Gosz, J. A social-ecological systems approach for environmental management. J. Environ. Manag. 2016, 178, 83-91. [CrossRef] [PubMed] 
49. Zicherman, H.; Cahaner, L. Modern Ultra-Orthodoxy: The Emergence of a Haredi Middle Class in Israel; The Israel Democracy Institute: Jerusalem, Israel, 2012; ISBN 978-965-519-114-1.

50. Fraser, E.; Dougill, AJ.; Mabee, W.E.; Reed, M.; McAlpine, P. Bottom up and top down: Analysis of participatory processes for sustainability indicator identification as a pathway to community empowerment and sustainable environmental management. J. Environ. Manag. 2006, 78, 114-127. [CrossRef] [PubMed]

51. Wang, X.; Montgomery, V.W.; Lebredo, N. Sustainability leadership in a local government context: The administrator's role in the process. Public Perform. Manag. Rev. 2014, 37, 339-364. [CrossRef]

52. Putnam, R.D. Bowling Alone: America's Declining Social Capital; Palgrave Macmillan: New York, NY, USA, 1995; pp. 223-234.

53. Dale, A.; Newman, L. Social capital: A necessary and sufficient condition for sustainable community development? Community Dev. J. 2008, 45, 5-21. [CrossRef]

54. Hitzhusen, G.E. Going green and renewing life: Environmental education in faith communities. New Dir. Adult Cont. Educ. 2012, 133, 35-44. [CrossRef]

55. Paul-Binyamin, I.; Reingold, R. Multiculturalism in teacher education institutes-The relationship between formulated official policies and grassroots initiatives. Teach. Teach. Educ. 2014, 42, 47-57. [CrossRef]

56. Hollweg, K.S.; Taylor, J.R.; Bybee, R.W.; Marcinkowski, T.J.; McBeth, W.C.; Zoido, P. Developing a Framework for Assessing Environmental Literacy; North American Association for Environmental Education: Washington, DC, USA. Available online: https: / www.naaee.net (accessed on 28 June 2018).

57. Orr, D. Ecological Literacy_Education and the Transition to a Postmodern World; State University of New York Press: Albany, NY, USA, 1992; ISBN 0-7914-0873-6.

58. Gal, R. The Haredi in the Israeli Society: Status 2014; Samuel Neaman Institute for National Policy Research, Technion: Haifa, Israel, 2015. (In Hebrew)

(C) 2018 by the authors. Licensee MDPI, Basel, Switzerland. This article is an open access article distributed under the terms and conditions of the Creative Commons Attribution (CC BY) license (http://creativecommons.org/licenses/by/4.0/). 